\title{
PROTOTIPE JARINGAN SYARAF TIRUAN UNTUK MENDETEKSI BANJIR MENGGUNAKAN METODE BACKPROPAGATION
}

\author{
Ramalia Noratama Putri ${ }^{1)}$ Debi Setiawan ${ }^{2)}$ \\ ${ }_{1,2}$ Teknik Informatika, STMIK Amik Riau, Jl. Purwodadi Km 10,5 Pekanbaru \\ email: noratamaramalia@gmail.com, debisetiawan9090@gmail.com
}

\begin{abstract}
The purpose of this research is to realize the flood detection tool in the form of prototype model which will be used to detect flood. The variables used in this research are rain intensity, water dispersion coefficient, wake area, and water surface area. The method used backpropagation because this method is suitable for flood detection process based on the variables used. This research produces a flood detection prototype in the form of flood simulation tool which can be developed to be the right tool. The results of this system prototype test has accuracy located on the microprocessor chip and ultrasonic sensor system that produces a $0.9 \%$ MSE level and $99.8 \%$ accuracy rate, to changes in water per second.
\end{abstract}

Keywords: Backpropagation, Prototype, Flood Detection

\begin{abstract}
Abstrak
Tujuan dari penelitian ini adalah untuk merealisasikan alat pendeteksi banjir berupa model prototipe yang akan digunakan untuk mendeteksi banjir. Variabel yang digunakan dalam penelitian ini antara lain Intensitas hujan, koefesien buangan air, luas area terbangun, luas genangan di permukaan air. Metode yang digunakan backpropagation karena metode ini cocok digunakan untuk melakukan proses deteksi banjir berdasarkan variable yang digunakan. Penelitian ini menghasilkan prototipe pendeteksi banjir berupa alat simulasi banjir yang dapat dikembangkan menajadi alat tepat guna. Hasil uji prototipe sistem ini memiliki keakurasian yang terletak pada chip microprocessor dan system sensor ultrasonik yang menghasilkan tingkat MSE 0.9\% dan tingkat keakurasian $99.8 \%$, terhadap perubahan ketinggian air perdetik.
\end{abstract}

Keywords: Backpropagation, Prototipe, Deteksi Banjir

\section{PENDAHULUAN}

Permasalahan yang selalu dihadapi masyarakat madani perkotaan kususnya di pekanbaru adalah masalah banjir. Ketika musim hujan tiba debit air sungai kampar naik, sehingga ketika bendungan dibuka maka akan terjadi banjir. Banjir dapat melumpuhkan aktifitas dan menelan korban jiwa. Berdasarkan permasalahan diatas maka sistem deteksi banjir dengan menggunakan metode backpropagation. Metode ini sangat tepat digunakan untuk penelitian ini karna menurut peneliti sebelumnya. Berdasarkan studi literatur yang telah dilakukan, bahwa metode jaringan syaraf tiruan telah banyak diterapkan dalam penelitian, diantaranya dapat dilihat dalam penelitian yang dilakukan oleh Pangastuti. Peneletian tersebut menggunakan metode Jaringan Syaraf Tiruan backpropagation untuk mengukur tingkat korelasi prestasi mahasiswa. Berdasarkan hasil penelitian tersebut, tingkat korelasi kecocokan antara target yang telah ditentukan dan target.

\section{TINJAUAN P USTAKA}

\section{A. Jaringan Syaraf Tiruan}

Jaringan Syaraf Tiruan adalah paradigma pengolahan informasi yang terinspirasi oleh sistem syaraf secara biologis, seperti proses informasi pada otak manusia. Elemen kunci dari paradigma ini adalah struktur dari sistem pengolahan informasi yang terdiri dari sejumlah besar elemen pemrosesan yang saling berhubungan (neuron), bekerja serentak untuk menyelesaikan masalah tertentu. Cara kerja JST seperti cara kerja manusia, yaitu belajar melalui contoh. 
Sebuah JST dikonfigurasikan untuk aplikasi tertentu, seperti pengenalan pola atau aplikasi data, melalui proses pembelajaran. Belajar dalam sistem biologis melibatkan penyesuaian terhadap koneksi synaptic yang ada antara neuron. Hal ini berlaku juga untuk JST [6].

\section{B. Algoritma Backpropagation}

Backpropagation adalah metode penurunan gradient untuk meminimilkan kuadrat error keluaran. Ada tiga tahap yang harus dilakukan dalam pelatihan jaringan, yaitu tahap perambatan maju (forward propagation), tahap perambatan balik, dan tahap perubahan bobot dan bias. Arsitektur jaringan ini tediri dari input layer, hidden layer, dan output layer [6].

Algoritma Backpropagation merupakan salah satu algoritma yang sering digunakan dalam menyelesaikan masalah-masalah yang rumit. Hal ini dimungkinkan karena jaringan dengan algoritma ini dilatih dengan menggunakan metode belajar terbimbing. Pada jaringan diberikan sepasang pola yang teridiri dari atas pola masukan dan pola yang dinginkan [7].

Tahap pelatihan dengan menggunakan metode backpropagation terdiri dari tiga fase, yaitu fase propagasi maju, fase propagasi mundur, dan fase perubahan bobot. Ketiga fase tersebut diulang terus menerus hingga kondisi penghentian dipenuhi. Umumnya kondisi penghentian yang sering dipakai adalah jumlah iterasi atau kesalahan atau target error [5].

Sebelum dilakukan pelatihan dan pengujian pada perhitungan prediksi menggunakan metode JST maka terlebih dahulu data yang akan dilatih dan diuji ditransformasikan. Tahapan transformasi merupakan tahapan untuk merubah data real menjadi data yang dibutuhkan dalam pelatihan Jaringan Syaraf Tiruan. Data yang akan dimasukkan pada Jaringan Syaraf Tiruan harus dinormalisasi terlebih dahulu. Proses normalisasi akan dilakukan terhadap input dan target.

Proses normalisasi ini berguna supaya Jaringan Syaraf Tiruan dapat mengenali data sehingga data-data input dan target yang telah ditentukan masuk dalam suatu range tertentu sehingga proses training pada Jaringan Syaraf Tiruan bisa lebih efektif serta efesien. Dalam kasus ini data akan ditransformasikan pada interval $[0,10,9]$ mengingat fungsi sigmoid merupakan fungsi asimtotik yang nilainya tidak pernah mencapai 0 ataupun 1.

Untuk mentransformasikan seluruh data real tersebut, digunakan fungsi sebagai berikut :

y $1=0.8(x-b) c-b+0.1(1)$

Di mana:

$\mathrm{a}=$ data minimum

$\mathrm{b}=$ data maksimum

$\mathrm{x}=$ nilai asli dari data

$\mathrm{x} 1$ = nilai transformasi dari data

Algoritma pelatihan untuk jaringan saraf tiruan Backpropagation ini adalah sebagai berikut [4] :

Langkah 0 : Inisialisasi nilai bobot dengan nilai acak yang kecil.

Langkah 1 : Selama kondisi berhenti masih tidak terpenuhi, laksanakan langkah 2 sampai 9.

Langkah 2 : Untuk tiap pasangan pelatihan, kerjakan langkah 3 sampai 8 .

a. Feedforward :

Langkah 3 : Untuk tiap unit masukan $(X i$, $i=1, \ldots, n)$ menerima sinyal masukan $x i$ dan menyebarkan sinyal itu ke seluruh unit pada lapis atasnya (lapis tersembunyi).

Langkah 4 : Untuk tiap unit tersembunyi $(Z j, \quad j=1, \ldots, p)$ dihitung nilai masukan dengan menggunakan nilai bobotnya :

$Z_{-} i n_{j}=V o_{j}+\sum_{i=1}^{n} X_{I} V_{i j}$

Kemudian dihitung nilai keluaran dengan menggunakan fungsi akti-vasi yang dipilih :

$z_{j}=f\left(z_{i n_{j}}\right)$ di mana fungsi aktivasi yang digunakan ialah fungsi sigmoid biner yang mempunyai persamaan :

$$
f 1(x)=\frac{1}{1+\exp (-z)}
$$

Hasil fungsi tersebut dikirim ke semua unit pada lapis di atasnya. 
Langkah 5 : Untuk tiap unit keluaran $\left(y_{k}\right.$, $k=1, . ., m)$ dihitung nilai masukan dengan menggunakan nilai bobot-nya :

$$
\begin{aligned}
& y_{\left(\text {in }_{k}\right.} \\
& =W_{o k}+\sum_{i=1}^{p} Z_{j} W j k
\end{aligned}
$$

Kemudian dihitung nilai keluaran dengan menggunakan fungsi aktivasi :

$$
y_{k}=\frac{1}{1+\exp (-y)}
$$

b. Perhitungan backward :

Langkah 6 : Untuk tiap unit keluaran $\left(y_{k}\right.$, $k=1, . ., m)$ menerima pola target yang bersesuaian dengan pola masukan, dan kemudian dihitung informasi kesalahan :

$$
\sigma_{k}=\left(t_{k}-y_{k}\right) f^{\prime}\left(y_{-i n_{k}}\right)
$$

Kemudian dihitung koreksi nilai bobot yang kemudian akan digunakan untuk memperbaharui nilai bobot wjk.:

$$
\Delta W_{j k}=\alpha \delta_{k} z_{j}
$$

Hitung koreksi nilai bias yang kemudian akan digunakan untuk memperbaharui nilai

$W_{0 k}$ :

$$
\Delta W_{0 k}=\alpha \delta_{k}
$$

dan kemudian nilai $\delta \mathrm{k}$ dikirim ke unit pada layer sebelumnya.

Langkah 7 : Untuk tiap unit tersembunyi $(Z j, \quad j=1, \ldots, p)$ dihitung delta masukan yang berasal dari unit pada layer di atasnya :

$$
\delta_{i n_{j}}=\sum_{k=1}^{m} \delta_{k} W_{j k}
$$

Di mana nilai tersebut dikalikan dengan nilai turunan dari fungsi aktivasi untuk menghitung informasi kesalahan :

$$
\delta_{j}=\delta_{i n_{j}} f^{\prime}\left(z_{i n_{j}}\right)
$$

Hitung koreksi nilai bobot yang kemudian digunakan untuk me perbaharui nilai vij:

$\Delta V_{i j}=a\left(\delta_{j} 2\right)_{i}$

dan hitung nilai koreksi bias yang kemudian digunakan untuk memperbaharui voj:

$$
\Delta V_{0 j}=\alpha \delta_{j}
$$

c. Memperbaharui nilaibbobot dan bias :

Langkah 8 : Tiap nilai bias dan bobot $(j=0, \ldots, p)$ pada unit keluaran $\left(y_{k}, k=1, \ldots, m\right)$ diperbaharui :

$W_{j k}($ new $)=W_{j k}($ old $)+$ $\Delta W_{j k}$ $V_{i j}($ new $)=V_{i j}($ old $)+\Delta V_{i j}$

Langkah 9 : Menguji apakah kondisi berhenti sudah terpenuhi. Kondisi berhenti ini terpenuhi jika nilai kesalahan yang dihasilkan lebih kecil dari nilai kesalahan referensi.

\section{Banjir}

Kawasan banjir di Kota Pekanbaru diantaranya terdapat di :

1. Kelurahan Sri Meranti,

2. Kecamatan Rumbai

3. Kelurahan Meranti Pandak

4. Kecamatan Rumbai Pesisir

5. Kelurahan Rejosari

6. Kecamatan Tenayan Raya

7. Kelurahan Tampan

8. Kecamatan Payung Sekaki dan di Harapan Raya

9. Kecamatan Tangkerang.

Ruas jalan yang sering terendam banjir yakni

1. Jalan Harmonis (9.a)

2. Kayangan 
3. Kecamatan Rumbai Pesisir

4. Jalan Riau ujung

5. Kecamatan Tampan

6. Jalan Garuda Sakti dan Jalan Air Hitam.

Variabel yang digunakan dalam penelitian ini antara lain :

1. Intensitas hujan

2. koefesien buangan air

3. luas area terbangun

4. luas genangan di permukaan air.

Deteksi banjir mempunyai tujuan untuk mendeteksi permasing-masing wilayah yang rawan banjir dengan meletakan alat yang dirancang di titik rawan banjir. Agar menjadi early warning atau peringatan dini untuk waspada banjir dan segera mencari tempat yang lebih tinggi.

\section{METODE PENELITIAN}

1. Identifikasi masalah

Permasalahan dalam penelitian ini adalah, bagaimana cara mendeteksi banjir. Untuk menyelesaikan masalah tersebut penulis menggunakan jaringan syaraf tiruan dengan algoritma backpropagation.

2. Kajian Pustaka

Setelah masalah dalam penelitian dianalisa, langkah selanjutnya yang dilakukan peneliti adalah melakukan studi literartur, yaitu membandingkan metode perhitungan yang telah dilakukan oleh peneliti sebelumnya, kelemahan dan keunggulan dari metode yang kita gunakan.

3. Pengambilan data

Mengumpulkan data Proses pengumpulan data terbagi menjadi dua yaitu data kuantitatif yaitu data yang kita dapatkan berdasarkan angka. Hal ini berguna untuk proses perhitungan ketepatan mendeteksi kenaikan air pada sustu tempat yang sudah ditentukan tadi. Data yang dikumpulkan adalah Intensitas hujan, koefesien buangan air, luas area terbangun, luas genangan di permukaan air.

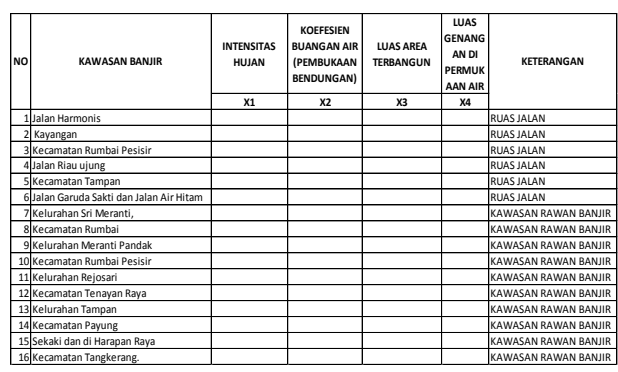

Keterangan :

$\mathrm{X} 1=$ Intensitas hujan

$\mathrm{X} 2=$ Koefesien buangan air

$\mathrm{X} 3=$ Luas area terbangun

$\mathrm{X} 4=$ Luas genangan di permukaan air

Target $=$ Deteksi banjir

4. Perhitungan Manual

Proses perhitungan secara manual dengan menggunakan algoritma backpropagation

5. Perancangan Pola JST

Pada proses ini, kita dapat menentukan Pola Jaringan Syaraf Tiruan berdasarkan variabel.

6. Perhitungan JST

Proses pelatihan dan pengujian pola JST. Pada proses ini setiap variabel yang kita gunakan nantinya akan kita lakukan proses pelatihan dan pengujian agar mendapatkan pola

terbaik dengan nilai eror terkecil.

7. Pengujian Prototipe JST

Cara melihat system mampu merealisasikan tujuan sebagai alat deteksi banjir dengan cara mensimulasikannya, dan melihat cara kerja alat sesuai atau tidak.

8. Evaluasi Prototipe JST

Evaluasi terhadap hasil perhitungan dengan jaringan syaraf tiruan menggunakan algoritma backpropagation, yaitu apakah jaringan syaraf tiruan dapat mendeteksi banjir.

9. Kesimpulan

Kesimpulan merupakan bentuk dari hasil penelitian yang sudah dilakukan. 


\section{IMPLEMENTASI ALGORITMA BACKPROPAGATION}

1. Proses Normalisasi

Proses normalisasi merupakan suatu langkah kerja dalam mememindahkan angka dari kolom menjadi baris dan dari bilangan bulat menjadi pecahan, hal ini dilakukan agar data tadi mudah untuk dilakukan proses perkalian bobot pada matlab karna memiliki angka pecahan atau dinormalisasikan.

\section{Data Input dan Target}

Sebelum proses pegolahan data

dilakukan, perlu dilakukan proses penetuan masukan (input) serta target atau hasil yang diinginkan dari proses pengolahan data, berikut data input dan target berdasarkan data beban kerja dosen yang telah dikumpulkan, sampel yang diambil adalah 15 sampel data kawasan banjir :

\section{HASIL DAN PEMBAHASAN}

Hasil dari sistem yang dibuat dapat dilihat sebagai berikut :

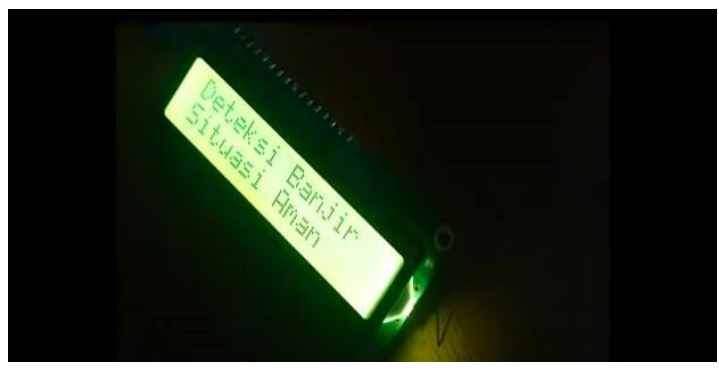

Gambar 1. Bentuk tampilan awal sistem

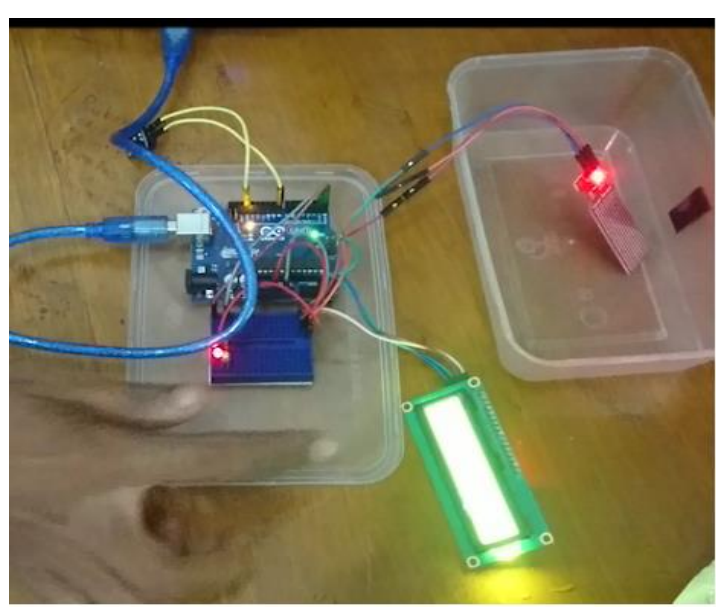

Gambar 2. Proses awal pemasangan alat

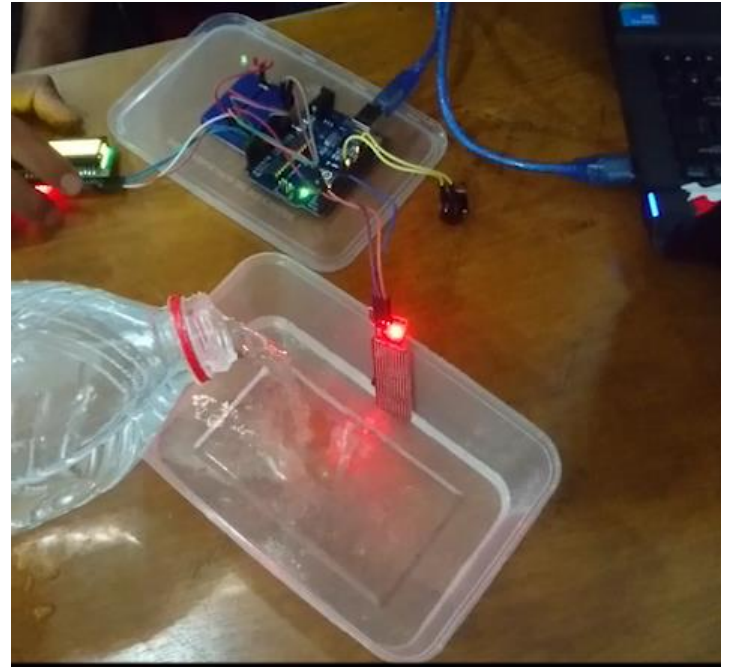

Gambar 3. Proses simulasi air mulai naik

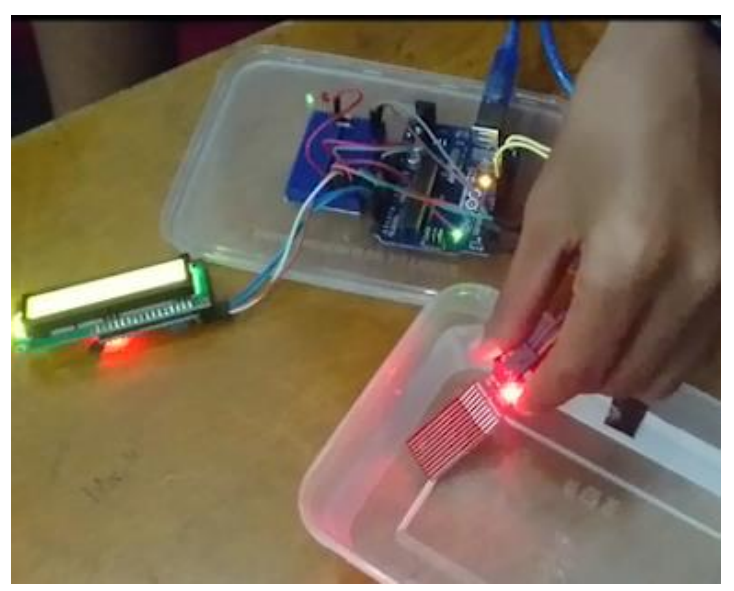

Gambar 4. Uji Sensor Deteksi didalam air

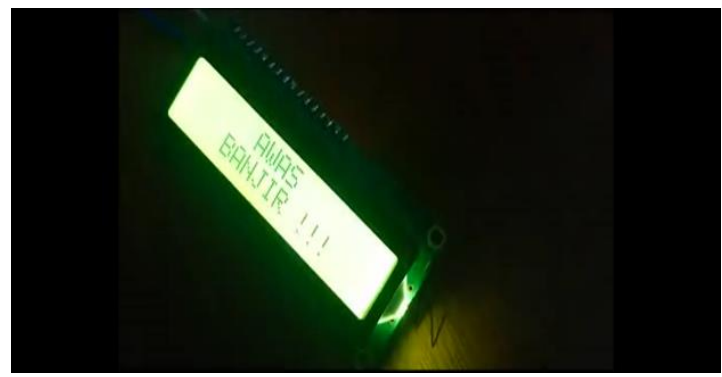

Gambar 5. Sistem menampilkan pesan ke layar LCD

Pembahasan dari sistem yang dibuat ini antara lain penerapan dari metode yang digunakan untuk mendukung dari ketepatan proses pengujian sistem sehingga saat dijalankan. 


\section{SIMPULAN}

Berdasarkan hasil dan implementasi, didapat kesimpulan bahwa jaringan syaraf tiruan menggunakan algoritma backpropagation dapat diterapkan dalam mendeteksi banjir.

\section{UCAPAN TERIMAKASIH}

Terimakasih kepada manajemen serta lembaga Badan Pusat Statistik (BPS), BPBD (Badan Penanggulangan Bencana Daerah) Provinsi Riau, serta pengelola jurnal STIKOM Pelita yang sudah mewujudkan penelitian ini.

\section{DAFTAR PUSTAKA}

[1] https://kalibanteng.wordpress.com/2009/11/ 14/analisis-variabel-variabel-penyebab-banjirgenangan-di-kecamatan-mijen-tugu-danngaliyan/

[2] Fatkuroji. (2013). Analisis Determinasi Minimnya Minat Dosen Dalam Penelitian Fatkuroji, 4, 33- 50.

[3] Pangastuti, P. (2010). Untuk Mengukur Tingkat Korelasi Prestasi Mahasiswa ( Studi Kasus Pada Universitas Dian Nuswantoro Semarang ).

[4] Sya'diyah, Z. (2015). No Title No Title. Statewide Agricultural Land Use Baseline 2015, 1. http//doi.org/10.1017/CBO9781107 415324.004

[5] Trimulya, A., Setyaningsih, F. A.,

Komputer, J. S., Elektro, J. T., Teknik, F., \& Tanjungpura, U. (2015). Implementasi jaringan syaraf tiruan metode backpropagation untuk memprediksi harga saham 1,3, 03(2), 66-75.

[6] T.Sutojo, S.Si, M. K., Edy Mulyanto,

S.Si, M. K., \& Suhartono, D. V. (2011). Kecerdasan Buatan. In Kecerdasan Buatan (1st ed., p. 466). yogyakarta: Andi.

[7] Matondang, Z. A., Tiruan, S., Mengukur, U., Korelasi, T., Syaraf, J., Dengan, T., ... Penentuan, U. (2013). Jaringan Syaraf Tiruan Dengan Algoritma.

[9] Budiman, M. J. (2013). Menggunakan Algoritma Backpropagation, 1-3. 